\title{
A rare case of acute myocardial infarction, related to mobile papillary fibroelastoma of the aortic valve
}

\author{
Zhuoqin Tang ${ }^{1}$, Mei Liu ${ }^{1}$, and He Huang ${ }^{1}$ \\ ${ }^{1}$ Sichuan University West China Hospital
}

December 1, 2020

\begin{abstract}
We present a case of a 75-year-old woman with typical myocardial infarction, however coronary angiogram was negative. Echocardiography identified the rare cause of chest pain, as a mobile mass of aortic valve was found to obstruct the coronary ostium. histopathology revealed a papillary fibroelastoma (PFE). Chest pain was relieved after surgical resection of the mass.
\end{abstract}

Title Page

Title:

A rare case of acute myocardial infarction, related to mobile papillary fibroelastoma of the aortic valve

Authors' names:

Zhuoqin Tang, MD, Mei Liu, MD, He Huang, MD, PhD

Department of cardiology, West China Hospital of Sichuan University, 37 Guo Xue Xiang, Chengdu, Sichuan, 610041, China.

\section{Word Count:1015}

\section{Corresponding author:}

He Huang, Department of cardiology, West China Hospital of Sichuan University, 37 Guo Xue Xiang, Chengdu, Sichuan, 610041, China, +86 0288542 2355,huanghe@wchscu.cn

Declaration of interst: We have no conflicts of interest to disclose.

Abstract : We present a case of a 75-year-old woman with typical myocardial infarction, however coronary angiogram was negative. Echocardiography identified the rare cause of chest pain, as a mobile mass of aortic valve was found to obstruct the coronary ostium. histopathology revealed a papillary fibroelastoma (PFE). Chest pain was relieved after surgical resection of the mass.

KEYWORDS: myocardial infarction, papillary fibroelastoma, aortic valve, echocardiography

INTRODUCTION: For patients clinically diagnosed acute myocardial infarction, but no significant stenosis of coronary arteries, the rare causes, such as cardiac valve tumors, should be considered. We report an unsual condition, in which obstruction of the coronary ostium by aortic PFE caused acute myocardial infarction.

CASE PRESENTATION: A 75-year-old woman, with a history of type 2 diabetes and hypertension for 10 years, and atrial fibrillation for 2 years, presented with chest pain for 12 hours, accompanying with dyspnea, sweating, and radiating pain in the shoulder and back. Physical examination revealed a standard heart rate and blood pressure(heart rate 68 beats/min, blood pressure 106/71mmHg), and no murmur was detected. 
Electrocardiogram showed sinus rhythm, ST-segment depression in V2 to V6, I, AVL, II, III, AVF and STsegment elevation in AVR. The CK-MB rose to $149.8 \mathrm{ng} / \mathrm{mL}$ (reference range $<2.88 \mathrm{ng} / \mathrm{mL}$ ) and troponin $\mathrm{T}$ increased up to $4852 \mathrm{ng} / \mathrm{L}$ (reference range $<14 \mathrm{ng} / \mathrm{L}$ ).

Coronary angiography, performed on the first day after admission, revealed that the left and right coronary arteries were not significantly narrow (Figure 1). During angiography, the patient developed shortness of breath and palpitations shortly, and ECG monitoring showed bradycardia and decreased blood pressure. CT angiogram on the second day after admission showed nodular filling defects in the aortic valve (Figure 2). At the same day, the transthoracic echocardiography (image not clear) revealed a mobile mass (size, $10 \mathrm{~mm} \times 6 \mathrm{~mm}$ ) of aortic valve. On the third day after admission, transesophageal echocardiography confirmed an isoechoic, regular, well-defined clump (size, $18 \mathrm{~mm} \times 12 \mathrm{~mm}$ ) on the left coronary cusp, suggesting of PFE (Figures 3 and 4, movie S1).

On the sixth day after admission, the aortic valve mass was removed under general anesthesia, extracorporeal circulation, along with aortic annuloplasty, and atrial fibrillation bipolar radiofrequency ablation. During the operation, a "sea anemone" pedicled clump (size, $18 \mathrm{~mm} \times 12 \mathrm{~mm}$ ), arising from the endocardium of the left coronary cusp very close to the commissure between the left and right coronary cusps, was suspected to intermittently block the left coronary opening (Figure 5). Postoperative pathology revealed PFE (Figure 6). The symptoms of chest pain was alleviated significantly after operation. No abnormality was found on the postoperative echocardiography and chest CT.

DISCUSSION: Papillary fibroelastoma is the most common primary cardiac valve tumor. ${ }^{1}$ As the analysis of 21 Cases by Ikegami and colleagues, ${ }^{2}$ Lesions are usually single, multiple lesions can involve solitary or multiple cusps.

The clinical manifestations of fibroelastomas range from asymptom to severe complications of embolism. Astonishingly, the tumor rarely cause valvular regurgitation or dysfunction. ${ }^{3,4}$ Most symptomatic cases show severe complications such as myocardial infarction, stroke, sudden death, and syncope. ${ }^{1,5}$ previous studies have shown these symptoms are related to either a mechanical obstruction, or embolisation of either papillary fibroelastoma fragments,or a thrombus formed on the tumour itself. ${ }^{1,5,6}$

ACS is usually accompanied with evidence of coronary artery stenosis, but in our case, no stenosis in coronary artery. We puzzled the reason for ACS, and ECHO gave an answer. PFE was the reason for ACS. Previously, Logan et al.$^{1}$ also reported a similar case about the cardiac papillary fibroelastomas (CPFs) presenting as AMI.

For the circumstance that patients developed bradycardia and hypotension during coronary angiography, presented with shortness of breath and palpitations, nevertheless without obvious chest pain, we speculate the mechanism as the passive movement of catheter to be advanced or retreated, rotated, pushed in the vascular cavity. these intravascular interventions may interfere the natural activities of papillary fibroelastoma and facilitate pushing the tumor to block the right coronary ostia, as Erdoes et al ${ }^{6}$ presented in their case. The primary blood supply to sinoatrial node is affected, resulting in dysfunction of the sinoatrial node.

Gender-related morbidity of CPFs is a matter of debate. A retrospective study of Innsbruck Medical University held that CPFs occured principally in men. ${ }^{7}$ however, some medical literature has shown more common in female ${ }^{5}$ the patient in our case is female.

Up to now, It has not been in agreement which coronary artery ostium is the most involved or which aortic valve CPFs predominately occur on. Erdoes et al. ${ }^{6}$ deemed the right coronary artery (RCA) was involved in the majority of the cases. In a retrospective and single-center study, Ikegami and colleagues ${ }^{2}$ reported that the noncoronary cusp of the AV was involved most often, consistent with the findings of Steger et al . ${ }^{7}$ However, fatal AMI even cardiogenic sudden death caused by CPF in many case are mainly reported in the left coronary valve. ${ }^{1,2}$ Besides our case report, in report of Logan and colleagues, ${ }^{1} \mathrm{CPF}$ causing myocardial infarction was also on left coronary cusp. anatomical factors may explain for this. The fibroelastoma located at the left coronary valve is closer to the left coronary ostia and easier to obstruct it, thereby seventy percent 
blood supply to heart is lacking and fatal cardiovascular events occur. In addition, Ikegami et al.$^{2}$ also repored a rare cardiac arrest caused by a CPF from left coronary cusp.

The advances in echocardiographic technology have resulted in CPFs' detection in an increasing number. ${ }^{2}$ Echocardiography is the primary modality for imaging intracardiac disease. ${ }^{8}$ CPFs' characteristics of echocardiography imaging-small size,pedical or stalk attachment to endocardium, mobile valvular/endocardial masses-make it likened to a sea anemone, ${ }^{3,6,8,9}$ which can help to identify a tumor as a PFE. Echocardiography has high value on diagnosing cardiac tumors, simultaneously assessing valve function with a CPF attached and measuring left ventricle function.

Fibroelastomas are easily detected and are well visualized at echocardiography as their distinguishable ,macroscopic, characteristic echocardiographic features, however they are usually not seen at CT or MR imaging because they are small and are attached to moving valves, ${ }^{8,9}$ which indicating echocardiography has an advantage over CT or MR imaging in identifying Fibroelastomas.

\section{References:}

Logan N, Islam MS, Chughtai JZ, et al. An atypical cause of myocardial infarction: case report of an obstructing papillary fibroelastoma of the aortic valve. Eur Heart J Case Rep. (2019) 3, 1-5.

Ikegami H, Andrei A-C, Li Z, et al. Papillary fibroelastoma of the aortic valve: analysis of 21 cases, including a presentation with cardiac arrest. Texas Hear Inst J 2015;42:131-135.

3. Klarich KW, Enriquez-Sarano M,Gura GM,et al.Papillary fibroelastoma: echocardiographic characteristics for diagnosis and pathologic correlation. J Am Coll Cardiol 1997; 30:784-790.

4. Baikoussis NG, Dedeilias P, Argiriou M, et al. Cardiac papillary fibroelastoma; when, how, why? Ann Card Anaesth 2016;19(1):162-5

5. Georghiou GP, Vidne BA, Sahar G, et al. Primary cardiac valve tumors. Asian Cardiovasc Thorac Ann. 2010;18(3):226-8.

6. Erdoes G, Stalder M, Basciani R, et al. An uncommon cause of coronary artery ostial obstruction: papillary fibroelastoma. Echocardiography. 2010;27(3):337-40.

1. Steger CM, Hager T, Ruttmann E. Primary cardiac tumours: a single-center 41-year experience. ISRN Cardiol 2012;2012:906109.

2. Araoz PA, Mulvagh SL, Tazelaar HD, et al. CT and MR imaging of benign primary cardiac neoplasms with echocardiographic correlation. RadioGraphics 2000; 20: 1303-19.

3. Han J, Xiang H, Ridley WE, et al. Anemone appearance: Papillary fibroelastoma. J Med Imaging Radiat Oncol. 2018;62 Suppl 1:12.

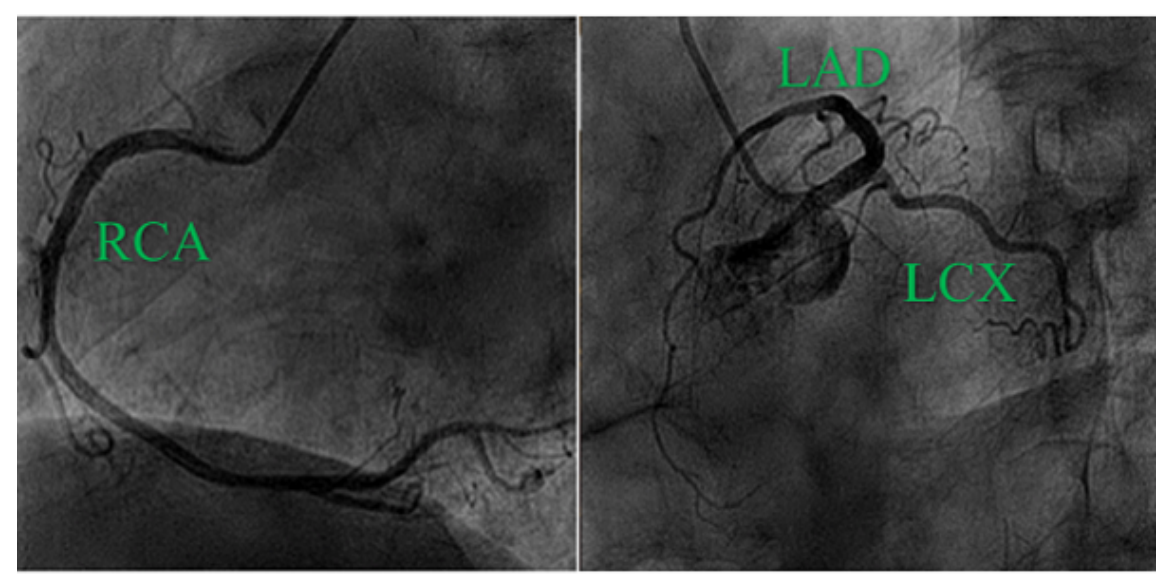



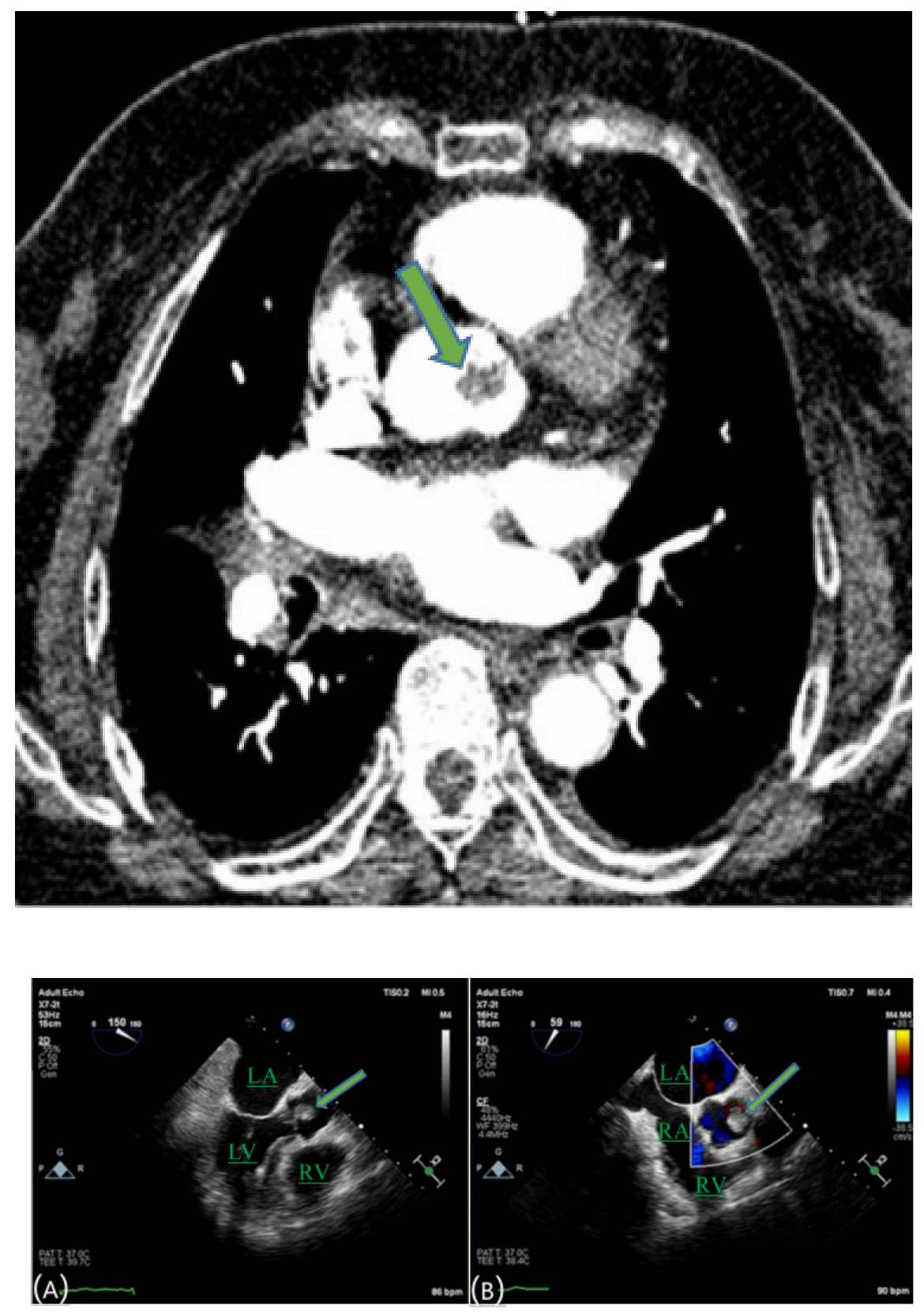

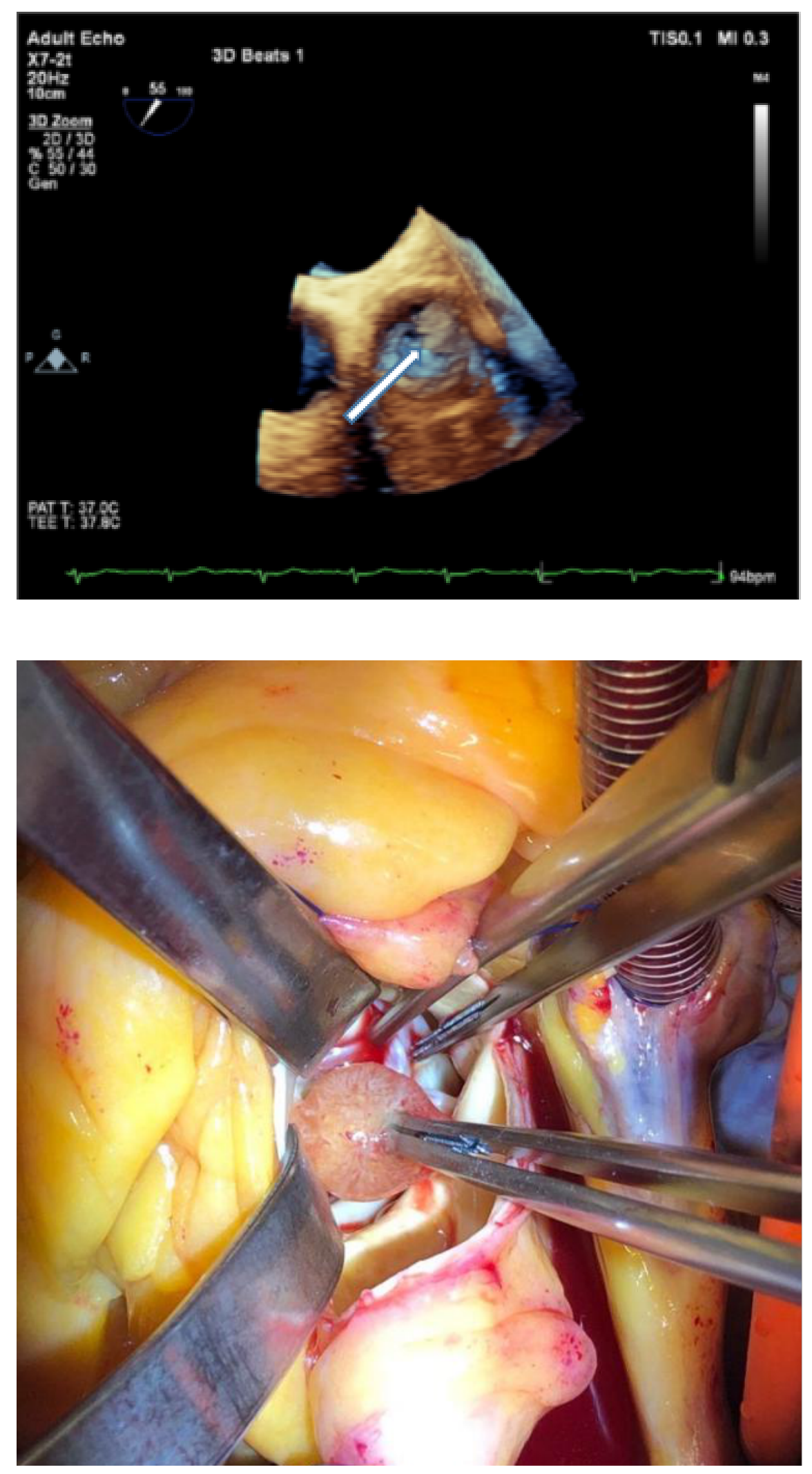


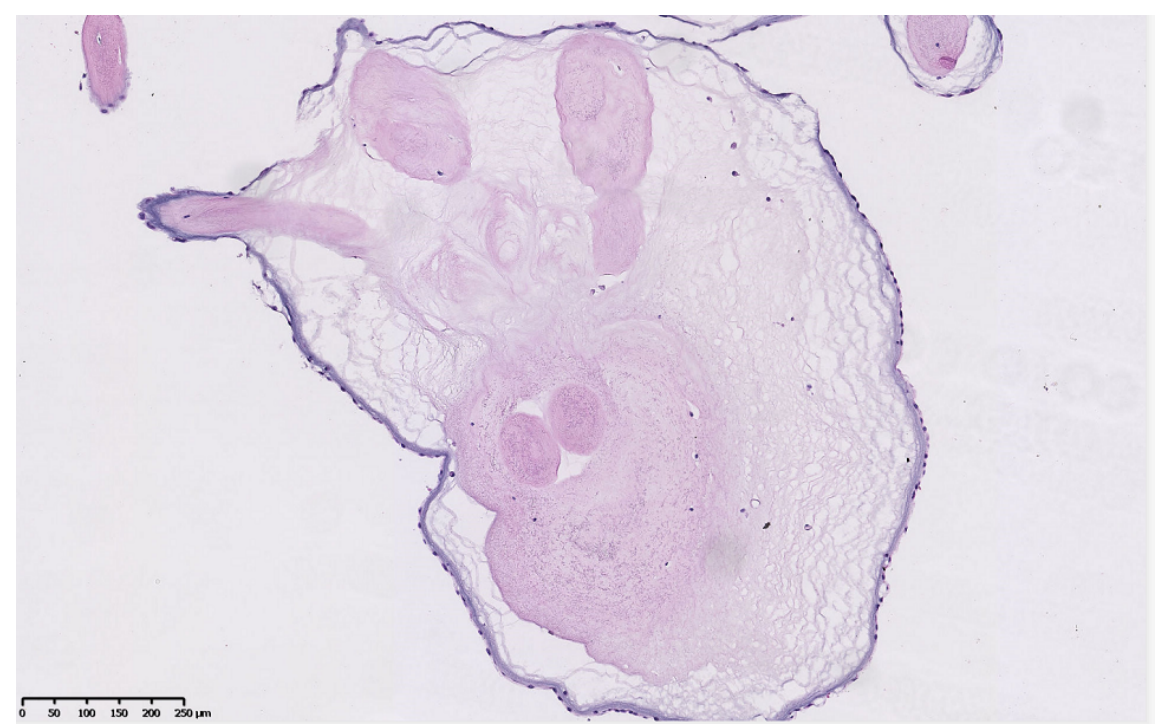

